\title{
Hydrophilic bile acids protect human blood-brain barrier endothelial cells from disruption by unconjugated bilirubin: an in vitro study
}

\author{
Inês Palmela ${ }^{1}$, Leonor Correia ${ }^{1,2}$, Rui F. M. Silva ${ }^{1,2}$, Hiroyuki Sasaki ${ }^{3}$ Kwang S. Kim ${ }^{4}$, \\ Dora Brites $^{1,2}$ and Maria A. Brito ${ }^{1,2 *}$ \\ ${ }^{1}$ Research Institute for Medicines (iMed.ULisboa), Faculdade de Farmácia, Universidade de Lisboa, Lisbon, Portugal, \\ ${ }^{2}$ Department of Biochemistry and Human Biology, Faculdade de Farmácia, Universidade de Lisboa, Lisbon, Portugal, \\ ${ }^{3}$ Division of Fine Morphology, Core Research Facilities, The Jikei University School of Medicine, Tokyo Japan, ${ }^{4}$ Division of \\ Infectious Diseases, Johns Hopkins University School of Medicine, Baltimore, MA, USA
}

OPEN ACCESS

Edited by:

Norman Ruthven Saunders,

University of Melbourne, Australia

Reviewed by:

Jean-François Ghersi-Egea, Institut National de la Santé et de la

Recherche Médicale, France Richard P. Wennberg,

Bilimetrix-USA, LLC, USA

${ }^{*}$ Correspondence:

Maria A. Brito,

Faculdade de Farmácia, Universidade de Lisboa, Research Institute for Medicines (iMed.ULisboa), Avenida Professor Gama Pinto, 1649-003 Lisbon, Portugal abrito@ff.ulisboa.pt

Specialty section: This article was submitted to Neurogenomics, a section of the journal Frontiers in Neuroscience

Received: 25 October 2014

Accepted: 24 February 2015

Published: 13 March 2015

Citation:

Palmela I, Correia L, Silva RFM Sasaki H, Kim KS, Brites D and Brito

MA (2015) Hydrophilic bile acids protect human blood-brain barrier endothelial cells from disruption by unconjugated bilirubin: an in vitro

study. Front. Neurosci. 9:80 doi: 10.3389/fnins.2015.00080
Ursodeoxycholic acid and its main conjugate glycoursodeoxycholic acid are bile acids with neuroprotective properties. Our previous studies demonstrated their anti-apoptotic, anti-inflammatory, and antioxidant properties in neural cells exposed to elevated levels of unconjugated bilirubin (UCB) as in severe jaundice. In a simplified model of the blood-brain barrier, formed by confluent monolayers of a cell line of human brain microvascular endothelial cells, UCB has shown to induce caspase-3 activation and cell death, as well as interleukin-6 release and a loss of blood-brain barrier integrity. Here, we tested the preventive and restorative effects of these bile acids regarding the disruption of blood-brain barrier properties by UCB in in vitro conditions mimicking severe neonatal hyperbilirubinemia and using the same experimental blood-brain barrier model. Both bile acids reduced the apoptotic cell death induced by UCB, but only glycoursodeoxycholic acid significantly counteracted caspase-3 activation. Bile acids also prevented the upregulation of interleukin- $6 \mathrm{mRNA}$, whereas only ursodeoxycholic acid abrogated cytokine release. Regarding barrier integrity, only ursodeoxycholic acid abrogated UCB-induced barrier permeability. Better protective effects were obtained by bile acid pre-treatment, but a strong efficacy was still observed by their addition after UCB treatment. Finally, both bile acids showed ability to cross confluent monolayers of human brain microvascular endothelial cells in a time-dependent manner. Collectively, data disclose a therapeutic time-window for preventive and restorative effects of ursodeoxycholic acid and glycoursodeoxycholic acid against UCB-induced blood-brain barrier disruption and damage to human brain microvascular endothelial cells.

Keywords: blood-brain barrier, glycoursodeoxycholic acid, human brain microvascular endothelial cells, interleukin-6, unconjugated bilirubin, ursodeoxycholic acid

Abbreviations: BBB, Blood-brain barrier; GUDCA, Glycoursodeoxycholic acid; HBMEC, Human brain microvascular endothelial cell; IL, Interleukin; SF, Sodium fluorescein; TUDCA, Tauroursodeoxycholic acid; UCB, Unconjugated bilirubin; UDCA, Ursodeoxycholic acid. 


\section{Introduction}

In neonatal life, increased levels and prolonged exposure to unconjugated bilirubin (UCB) may trigger bilirubin-induced neurological dysfunction (Cohen et al., 2010). Although the mechanisms underlying neurological dysfunction are still unclear, the understanding of UCB-induced neurotoxicity has increased greatly in the past years (Brites and Brito, 2012). A general impairment of membrane structure, properties, and function (Rodrigues et al., 2002b; Brito et al., 2004), with neuronal oxidative stress, the release of pro-inflammatory cytokines by glial cells and altered myelinogenesis have been demonstrated (Silva et al., 2002, 2010; Falcão et al., 2006; Fernandes et al., 2006; Brito et al., 2008; Vaz et al., 2010; Barateiro et al., 2014). The awareness of the important role of the blood-brain barrier (BBB) and particularly of brain microvascular endothelial cells (BMEC) in the course of bilirubin-induced neurological dysfunction has also grown. In fact, the influence of UCB on porcine and rat BMEC (Akin et al., 2002; Cardoso et al., 2012) and in a mouse BMEC line (Kapitulnik et al., 2012) revealed that UCB induces a loss of endothelial cell viability. Our recent studies on human BMEC (HBMEC) have shown that UCB decreases endothelial cell survival and induces the release of cytokines, such as interleukin-6 (Palmela et al., 2011), which are known to be involved in BBB disruption in pathological conditions (Kaur and Ling, 2008; Carvey et al., 2009). Furthermore, HBMEC exposure to UCB resulted in biphasic effects depending on the time of interaction, where prolonged incubation compromised the endothelial junctions and led to significant impairment of barrier integrity (Palmela et al., 2012). Interestingly, UCB-induced disruption of barrier properties of BMEC was observed even in the presence of astrocytes (Cardoso et al., 2012), an in vitro co-culture model that better resembles the in vivo condition. Importantly, these in vitro evidences have been confirmed in autopsy studies of a kernicterus premature infant presenting increased vascularization and infiltration of erythrocytes and albumin in the brain parenchyma (Brito et al., 2013). Moreover, recent studies of additional cases of kernicterus have shown that the most susceptible brain regions to UCB toxicity, as the cerebellum, hippocampus, and basal ganglia, present marked signs of $\mathrm{BBB}$ dysfunction, as reduced pericyte vascular coverage and alterations in the basement membrane (Palmela et al., submitted). Thus, these features point to an enhanced permeability of the vascular walls, at least in severely ill pre-term infants with bilirubin encephalopathy.

The bile acid ursodeoxycholic acid (UDCA), which exists in very low levels in the circulation in humans, is largely used as therapy for chronic liver diseases involving cholestasis (Poupon et al., 1994; Brites et al., 1998; Lazaridis et al., 2001). UDCA is conjugated in the liver originating tauroursodeoxycholic acid (TUDCA) and glycoursodeoxycholic acid (GUDCA), the latest accounting for approximately $80 \%$ of the bile acid conjugates produced in patients under therapy (Rudolph et al., 2002). In addition, a four-fold increase of GUDCA relatively to that of TUDCA was found in the bile of patients with complete extrahepatic biliary obstruction treated with UDCA (Rudolph et al., 2002). Several studies have suggested a potential role of UDCA in the treatment of non-liver diseases involving increased levels of apoptosis (Keene et al., 2002; Rodrigues et al., 2003) due to the anti-apoptotic properties of this bile acid (Amaral et al., 2009b). Interestingly, the anti-apoptotic properties of UDCA were recently demonstrated in osteoblasts exposed to bilirubin (Ruiz-Gaspa et al., 2014). Our own studies have shown that UDCA and GUDCA protect astrocytes from apoptosis and suppress the production of pro-inflammatory cytokines (Rodrigues et al., 2000; Silva et al., 2001b; Fernandes et al., 2007a) while also counteracting UCB-induced neuronal death and synaptic changes (Silva et al., 2012). Moreover, GUDCA abrogated UCBinduced alterations in the redox status, mitochondrial dysfunction and energy impairment in neurons (Brito et al., 2008; Vaz et al., 2010). Interestingly, the mechanism of action of UDCA and its conjugates appears to rely on the stabilization of the cell membrane structure and maintenance of its dynamic properties, derived from their ability to prevent alterations in membrane lipid polarity and fluidity, as well as in the protein order and redox status (Rodrigues et al., 2001, 2002b; Solá et al., 2002).

In regard to the beneficial effects of these bile acids on endothelial cells, little is known. Nevertheless, it was shown that TUDCA is able to protect against amyloid- $\beta$-induced apoptosis (Viana et al., 2009) and leukocyte rolling and adhesion to the endothelium induced by lipid peroxidation products (Vladykovskaya et al., 2012), as well as to promote vessel repair (Cho et al., 2015). Interestingly, UDCA was shown to inhibit endothelin-1 production (Ma et al., 2004) and to have an antiangiogenic capacity (Suh et al., 1997; Woo et al., 2010), suggesting an influence on endothelial cells in a much more complex manner. However, it remains unknown whether protective effects of UDCA and GUDCA are exerted on the endothelial cells of the human BBB, and specifically toward UCB-induced injury. Thus, we here aimed to first evaluate if such bile acids are able to protect HBMEC from UCB-induced apoptosis and ultrastructural changes. Next, we intended to investigate if UDCA and GUDCA are able to prevent the production of a mediator of endothelial permeability, interleukin-6, as well as changes in barrier integrity induced by UCB. By treating cells with UDCA and GUDCA prior to UCB exposure, or 4 and $8 \mathrm{~h}$ after the initiation of the incubation procedure, our purpose was to establish the therapeutic window of opportunity to be used in jaundiced infants at risk of bilirubin-induced neurological dysfunction requiring complementary medicines to the conventional treatments.

\section{Materials and Methods}

\section{Chemicals}

The basal medium Roswell Park Memorial Institute 1640, antibiotic-antimycotic solution, human serum albumin (fraction V, fatty acid free), bovine serum albumin, Hoechst 33258 dye, sodium fluorescein and UCB were purchased from Sigma Chemical Co. (St. Louis, MO, USA). Non-essential amino acids, sodium pyruvate, L-glutamine, fetal bovine serum and minimum essential medium vitamins were from Biochrom AG (Berlin, Germany). Nuserum IV and rat-tail collagen I were acquired from BD Biosciences (Erembodegem, Belgium). TRIzol Plus RNA Purification Kit, was from Invitrogen (Carlsbad, CA, USA). 
Caspase-3 substrate and Ac-Asp-Glu-Val-Asp- $p$-nitroanilide, were acquired from Calbiochem (San Diego, CA, USA). DuoSet ELISA kit was from R\&D systems (Minneapolis, MN, USA). Primers for real-time PCR analysis were purchased from Thermo Scientific (Soeborg, Denmark). RevertAid H Minus First Strand cDNA synthesis and Maxima SYBR Green qPCR Master Mix $(2 \times)$ were obtained from Fermentas (Burlington, ON, Canada). All other chemicals were of analytical grade and were purchased from Merck (Darmstadt, Germany).

\section{Cell Culture and Treatment}

To test whether UCB-induced injury to endothelial cells could be abrogated in the presence of UDCA and GUDCA, we used a HBMEC line as a simplified model of the human BBB. This cell line was derived from primary cultures of HBMEC transfected with SV40 large T antigen (Stins et al., 2001) and was recently proved to be the most suitable human cell line for an in vitro BBB concerning barrier tightness (Eigenmann et al., 2013). Cells were cultured in Roswell Park Memorial Institute medium supplemented with $10 \%$ fetal bovine serum, $10 \%$ NuSerum IV, $1 \%$ nonessential amino acids, $1 \%$ minimum essential medium vitamins, $1 \mathrm{mM}$ sodium pyruvate, $2 \mathrm{mM}$ L-glutamine, and $1 \%$ antibioticantimycotic solution, seeded at a density of $8 \times 10^{4} \mathrm{cell} / \mathrm{mL}$ in collagen I-coated coverslips or plates and treated after 2 days in culture, as previously described (Palmela et al., 2011). For integrity studies, based on the measurement of paracellular permeability to sodium fluorescein, cells were seeded on collagen I-coated polyester transwell inserts $(0.4 \mu \mathrm{m}$, Corning Costar Corp., USA) at a density of $8 \times 10^{4}$ cell/insert and treated after 8 days in culture (Palmela et al., 2012). Endothelial cultures were maintained at $37^{\circ} \mathrm{C}$ in a humid atmosphere enriched with $5 \% \mathrm{CO}_{2}$, and all experiments were performed at confluence.

UCB was purified (Mcdonagh and Assisi, 1972) and a $10 \mathrm{mM}$ stock solution was prepared in $0.1 \mathrm{M} \mathrm{NaOH}$ and used immediately after preparation. The $\mathrm{pH}$ value was restored to 7.4 by addition of equal amounts of $0.1 \mathrm{M} \mathrm{HCl}$, and all the procedures were performed under light protection to avoid photodegradation. Confluent monolayers of the HBMEC line were incubated with $100 \mu \mathrm{M} \mathrm{UCB}$, or with no addition (control), in the presence of $100 \mu \mathrm{M}$ human serum albumin. This experimental condition mimics the bilirubin/albumin ratio (1:1 molar ratio; $8.7 \mathrm{mg} / \mathrm{g})$ found in a kernicterus case described by us (Brito et al., 2012) and is within the $5.4-21.0 \mathrm{mg} / \mathrm{g}$ ratio recently associated to acute bilirubin encephalopathy in Egypt (Iskander et al., 2014). Determination of unbound bilirubin, or free bilirubin, by the widely used peroxidase method (Roca et al., 2006) showed that this experimental condition corresponds to a free bilirubin concentration of $23.6 \mathrm{nM}$, as previously reported by Palmela et al. (2012). The free bilirubin level used in the present in vitro model is within the range of values found by us in a group of moderately jaundiced neonates $(19.1 \pm 1.5 \mathrm{nM})$ (Brito, 2001) and by Ahlfors et al. (2009) (21-51 nM) in babies readmitted for jaundice. Also to mention that the apparent discrepancy between the free bilirubin value obtained in our lab and those indicated by Roca et al. (2006) may result from the fact that Roca et al. (2006) did not include cells in their system, thus not considering the fraction of bilirubin that is bound/included in cells (Brito et al., 2000; Palmela et al.,
2012), nor the non-conjugating pathways for UCB catabolism (Ahlfors et al., 2009). The incubation period used for each parameter varied between 1 and $48 \mathrm{~h}$, based on the time to obtain the maximal effect observed in prior studies (Palmela et al., 2011, 2012). The incubation medium consisted in the regular medium without fetal bovine serum and Nuserum IV, to avoid disturbance of the final concentration of albumin in the incubation medium.

Co-incubation studies were also performed with the bile acids UDCA and GUDCA, molecules with octanol/water partition coefficients of 1000 for the unconjugated form and 105 for the glycine-amidated molecule, and $\log \mathrm{P}$ values of 3.0 and 2.02 for the former and the later, respectively (Roda et al., 1990). In the coincubation studies, UDCA or GUDCA were added at a final concentration of $50 \mu \mathrm{M}$, which is found in the circulation of patients under therapy with UDCA. In particular, the concentration of $50 \mu \mathrm{M}$ GUDCA is commonly found in the serum of patients after treatment with UDCA at a dose of 13-15 mg per kilogram of body weight per day (Podda et al., 1990; Poupon et al., 1994; Brites et al., 1998). We previously showed that such concentration is not toxic to neurons (Silva et al., 2001b) and, most importantly, has beneficial properties in preventing neurodegeneration (Brito et al., 2008; Vaz et al., 2010). The bile acids were added at three different time points: $1 \mathrm{~h}$ prior to UCB addition and at 4 or $8 \mathrm{~h}$ after UCB incubation. For short periods of UCB incubation only the effects of $1 \mathrm{~h}$ pre-incubation with the bile acids were evaluated. Appropriate controls including cells treated with UDCA and GUDCA (without UCB) were also included to ascertain the absence of toxicity of these molecules.

For the integrity experiments, endothelial cells were cultured on semipermeable filters inserted in the culture plate well. With this system, there are two compartments: the apical or upper one that can be considered as the "blood-side," where UCB, bile acids and human serum albumin were added, and the basal or lower compartment, which is considered the "brain side."

\section{Assessment of Apoptosis}

Caspase-3 activity and the number of apoptotic nuclei were determined after 4 and $48 \mathrm{~h}$ of UCB exposure, respectively, since these time points represent the maximum effects of UCB alone (Palmela et al., 2011).

Activity of caspase- 3 was measured by a colorimetric method (Calbiochem, Darmstadt, Germany), as usual in our lab (Palmela et al., 2011). The results were expressed as fold change from control values. Assessment of nuclear morphology of the HBMEC line following Hoechst 33258 staining was evaluated as previously described (Palmela et al., 2011). Fluorescence was visualized using a Leica DFC 490 camera (Leica, Wetzlar, Germany) adapted to an AxioScope.A1 microscope (Zeiss, Göttingen, Germany). Values were expressed as percentage of apoptotic nuclei.

\section{Transmission Electron Microscopy}

Ultrastructural analysis was performed by transmission electron microscopy following $48 \mathrm{~h}$ exposure to UCB in HBMEC pretreated with UDCA or GUDCA. Cells were fixed with $1.2 \%$ glutaraldehyde in $0.1 \mathrm{M}$ phosphate buffer and $1 \%$ osmium tetroxide in the same buffer, dehydrated with a graded series of ethanol, and 
then embedded in epoxy resin. Ultrathin sections were stained with uranyl acetate and lead citrate and observed with a Hitachi H-7500 transmission electron microscope (Tokyo, Japan) at an acceleration voltage of $80 \mathrm{kV}$.

\section{Measurement of Interleukin-6 mRNA Expression and Protein Release}

The HBMEC line was exposed to UCB for $1 \mathrm{~h}$ for mRNA analysis, and for $4 \mathrm{~h}$ for cytokine release quantification, since the maximum effects of UCB alone in interleukin-6 expression and secretion were observed at these time points (Palmela et al., 2011).

Analysis of mRNA expression was performed by quantitative real time PCR using a SYBR Green qPCR Master Mix $(2 \times)$, as described previously (Palmela et al., 2011). This assay was performed using $\beta$-actin as an endogenous control to normalize the expression level of interleukin-6 mRNA. The following sequences were used as primers: interleukin6 sense, 5'-GACAGCCACTCACCTCTTCA- $3^{\prime}$ and anti-sense, $5^{\prime}$-TTCACCAGGCAAGTCTCCTC-3' (Wang et al., 2006); $\beta$ actin sense, 5'-ACAGAGCCTCGCCTTTGCCG-3' and antisense, 5'-TGGGCCTCGTCGCCCACATA-3' (NM_001101.3). Non-specific products of PCR were not found in any case. The relative quantification was made using the Pfaffl modification of the $\Delta \Delta \mathrm{C}_{\mathrm{T}}$ equation $\left(\mathrm{C}_{\mathrm{T}}\right.$, cycle number at which the fluorescence passes the threshold level of detection), taking into account the efficiencies of individual genes. The results were normalized to $\beta$ actin and the initial amount of the template of each sample was determined as fold change from control samples (reference).

Endothelial interleukin-6 release was assessed in duplicate, using a specific DuoSet ELISA development kit, according to the manufacturer's instructions. Measurements were obtained at a wavelength of $450 \mathrm{~nm}$, with a reference filter of $620 \mathrm{~nm}$, using a microplate reader. The average control values were $135 \mathrm{pg} / \mathrm{mL}$ and the results were expressed as fold change from control.

\section{Evaluation of Barrier Integrity by Permeability Measurement}

The capacity of UDCA and GUDCA to modulate permeability was evaluated in cells treated with UCB for $48 \mathrm{~h}$, the time-point resulting in the maximum disruption of the integrity state of HBMEC monolayer by UCB (Palmela et al., 2012).

In our previous studies, we found that UCB increases the permeability to sodium fluorescein (Palmela et al., 2012), a low molecular weight tracer $(376 \mathrm{Da})$, but not to albumin-bound Evans blue, a high molecular weight tracer $(68 \mathrm{kDa})$. So, in this study HBMEC paracellular permeability assay was conducted with sodium fluorescein as previously described (Veszelka et al., 2007; Cardoso et al., 2012; Palmela et al., 2012). Briefly, cell culture inserts were transferred to 12 -well plates containing RingerHepes solution $(118 \mathrm{mM} \mathrm{NaCl}, 4.8 \mathrm{mM} \mathrm{KCl}, 2.5 \mathrm{mM} \mathrm{CaCl}$, $1.2 \mathrm{mM} \mathrm{MgSO}_{4}, 5.5 \mathrm{mM}$ D-glucose, $20 \mathrm{mM}$ Hepes, $\mathrm{pH}$ 7.4) in the basal compartments. The sodium fluorescein solution (10 $\mathrm{mg} / \mathrm{mL}$ sodium fluorescein in Ringer-Hepes) was added to the upper chambers. The inserts were transferred to new wells at 20, 40, and $60 \mathrm{~min}$. Lower chamber solutions were collected to determine sodium fluorescein levels (Hitachi F-2000 fluorescence spectrophotometer, excitation: $440 \mathrm{~nm}$ and emission: $525 \mathrm{~nm}$ ). Flux across cell-free inserts was also measured. The endothelial permeability coefficient was calculated as previously described (Deli et al., 2005) and the average control permeability coefficient was $1.4 \times 10^{-5} \mathrm{~cm} / \mathrm{s}$.

\section{Assessment of UDCA and GUDCA Passage across the HBMEC Monolayer}

To establish whether UDCA and GUDCA are able to cross the BBB endothelium, a two-chamber culture system was used. Bile acids were added to the upper chambers and media from the lower chambers were collected after 4 and $48 \mathrm{~h}$ of incubation. The bile acid passage across the HBMEC monolayer was evaluated by measuring the concentrations of UDCA and GUDCA by an enzymatic-fluorimetric assay (Brites et al., 1998). Results were shown as average concentration $(\mu \mathrm{M}) \pm \mathrm{SEM}$.

\section{Statistical Analysis}

Results are expressed as means \pm SEM values from, at least, three separate experiments. Differences between groups were determined by one-way ANOVA with Bonferroni post-test, using Prism 5.0 (GraphPad Software, San Diego, CA). Statistical significance was considered when $P$-values were lower than 0.05 .

\section{Results}

\section{UDCA and GUDCA Protect HBMEC from UCB-Induced Apoptosis, but only GUDCA is Effective in Reducing Caspase-3 Activation}

UCB-induced apoptosis in the HBMEC line includes the presence of apoptotic features that increased with the time of exposure and reached maximal levels at $48 \mathrm{~h}$ (Palmela et al., 2011). Thus, this time was chosen to evaluate the ability of UDCA and GUDCA to protect HBMEC from UCB-induced apoptosis. The bile acids were added at three different time points, evaluating their potential when added before and after the injury. Addition of UDCA and GUDCA reduced UCB injury, regardless of the time of addition (Figure 1). This protective effect was maximal in the treatments with GUDCA, especially when added at $1 \mathrm{~h}$ prior to UCB addition (54\% reduction from UCB values, $P<0.001$, vs. $42 \%$ for UDCA at the same time point, $P<0.01$ ). Importantly, bile acids partially reverted UCB injury with a nearly $30 \%$ protection rate reduction compared to UCB damage (Figure 1), when added $8 \mathrm{~h}$ after UCB addition.

We next assessed the preventive bile acid effect on caspase- 3 activity at $4 \mathrm{~h}$, the time point where the maximal effect of UCB on endothelial cells was observed (Palmela et al., 2011). As seen in Figure 2, only GUDCA was able to significantly protect from UCB-induced activation of caspase-3 $(P<0.05)$.

\section{Ultrastructural Changes Induced by UCB in HBMEC are Abrogated by UDCA and GUDCA}

Based on the UCB-induced effects on apoptosis after $48 \mathrm{~h}$ incubation and the rescue ability of both UDCA and GUDCA to partially restore cell functionality, we decided to further assess whether changes at HBMEC ultrastructural level were produced 


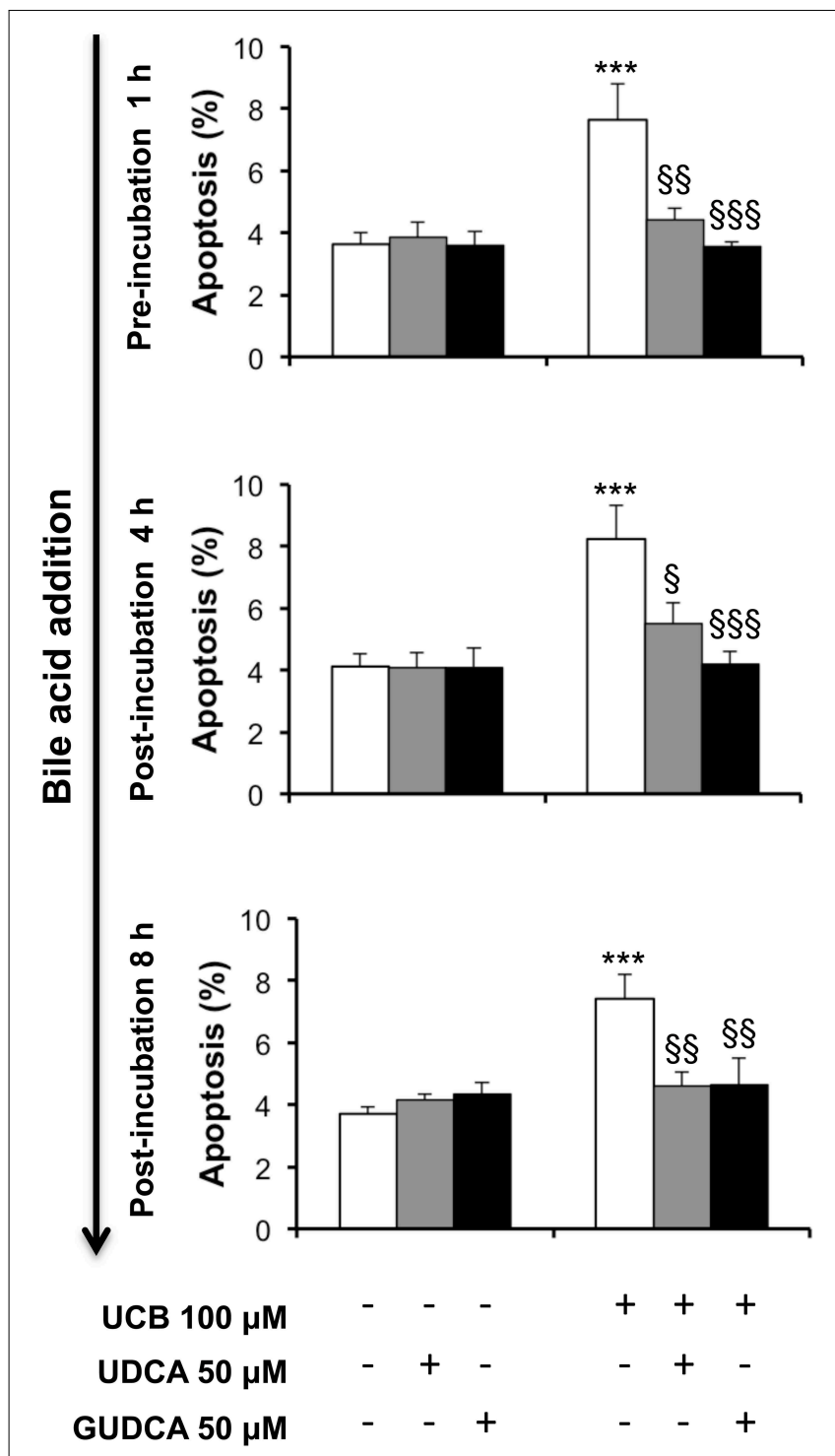

FIGURE 1 | Ursodeoxycholic acid (UDCA) and glycoursodeoxycholic acid (GUDCA) protect human brain microvascular endothelial cells (HBMEC) from unconjugated bilirubin (UCB)-induced apoptosis. A cell line of HBMEC was incubated without (control) or with $100 \mu \mathrm{M} \cup \mathrm{CB}$, in the presence of $100 \mu \mathrm{M}$ human serum albumin, for $48 \mathrm{~h}$. The bile acids $(50 \mu \mathrm{M})$ were added prior to ( $1 \mathrm{~h}$ ) or after ( 4 or $8 \mathrm{~h}$ ) UCB addition. Quantification of apoptosis is shown as percentage of apoptotic nuclei per total number of cells and results are expressed as mean \pm SEM from at least three independent experiments. ${ }^{* * *} P<0.001$ vs. control; ${ }^{\S} P<0.05$, ${ }^{\S} P P<0.01$, and $\S \S \S P 0.001$ vs. UCB alone.

by UCB and prevented by bile acid treatment. The transmission electron microscopy analysis revealed a marked reduction in the amount of ribosomes in UCB-treated cells, with an evident recovery in the presence of both bile acids (Figure 3). The same occurred relatively to cellular fragments detaching from the cultured HBMEC and mitochondrial cristae disruption observed, showing the damaging effects of UCB, once again markedly reduced in the presence of each of the bile acids.

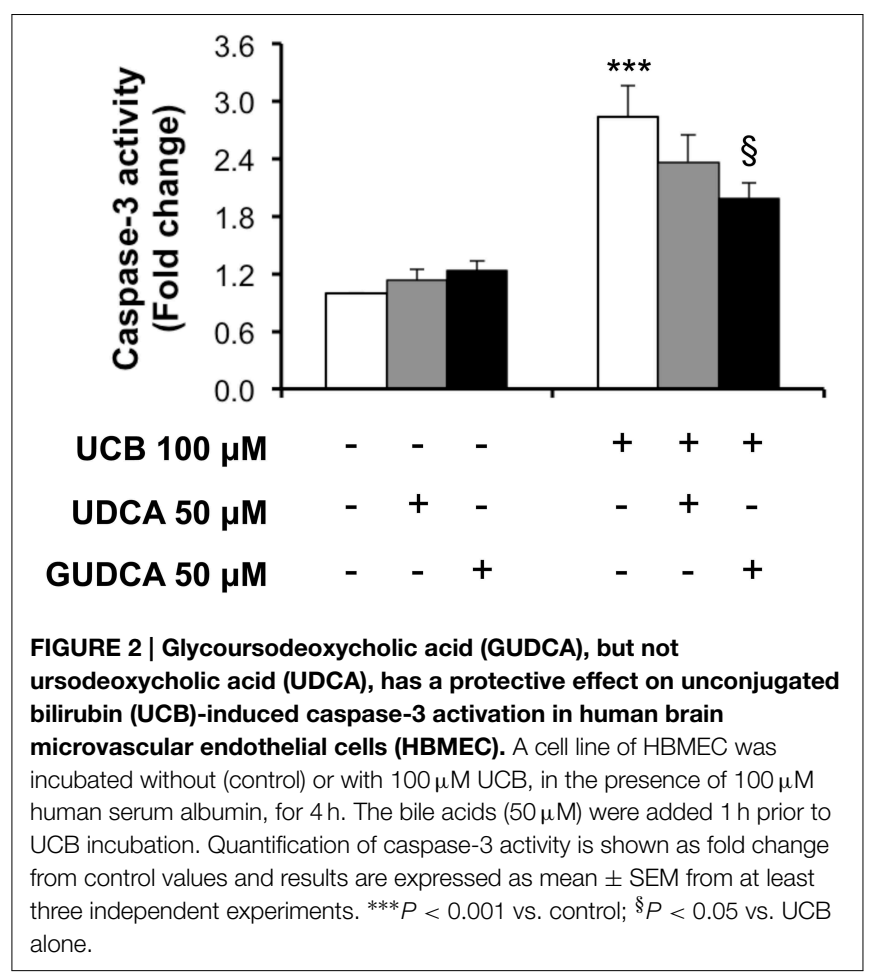

\section{UCB-Induced Increase of Interleukin-6 mRNA and Cytokine Expression in HBMEC is More Effectively Reduced by UDCA than by GUDCA}

One of the important effects of UCB on HBMEC previously observed by us was the upregulation of interleukin- 6 mRNA levels and protein secretion (Palmela et al., 2011). This previous work indicated that UCB induced the maximum cytokine secretion at $4 \mathrm{~h}$, while the highest mRNA expression was at $1 \mathrm{~h}$ following UCB exposure. These time points were then selected and the bile acids were added $1 \mathrm{~h}$ prior to UCB incubation. As seen in Figure 4, both bile acids abrogated interleukin- 6 mRNA upregulation (Figure 4A), with reductions from UCB values of $27 \%$ for GUDCA $(P<0.05)$ and $46 \%$ for UDCA $(P<0.001)$. On the other hand, only UDCA showed preventive effects on UCB-induced release of interleukin-6 (Figure 4B), decreasing UCB-induced cytokine secretion by $35 \%(P<0.001)$.

\section{UDCA and GUDCA Prevent and Rescue Disruption of HBMEC Integrity by UCB}

The ability of the tested bile acids to counteract UCB-induced upregulation of interleukin-6, led us to hypothesize that UDCA and GUDCA would protect against the consequent endothelial hyperpermeability. Thus, we measured the paracellular permeability to the low molecular weight compound, sodium fluorescein. This is a widely used indicator of the barrier properties, with several studies showing increased values in conditions associated with hyperpermeability (Hülper et al., 2013; Labus et al., 2014). In our previous study we showed that this parameter is significantly enhanced upon prolonged UCB exposure (Palmela et al., 2012), as also observed in the present study (Figure 5). Here, 


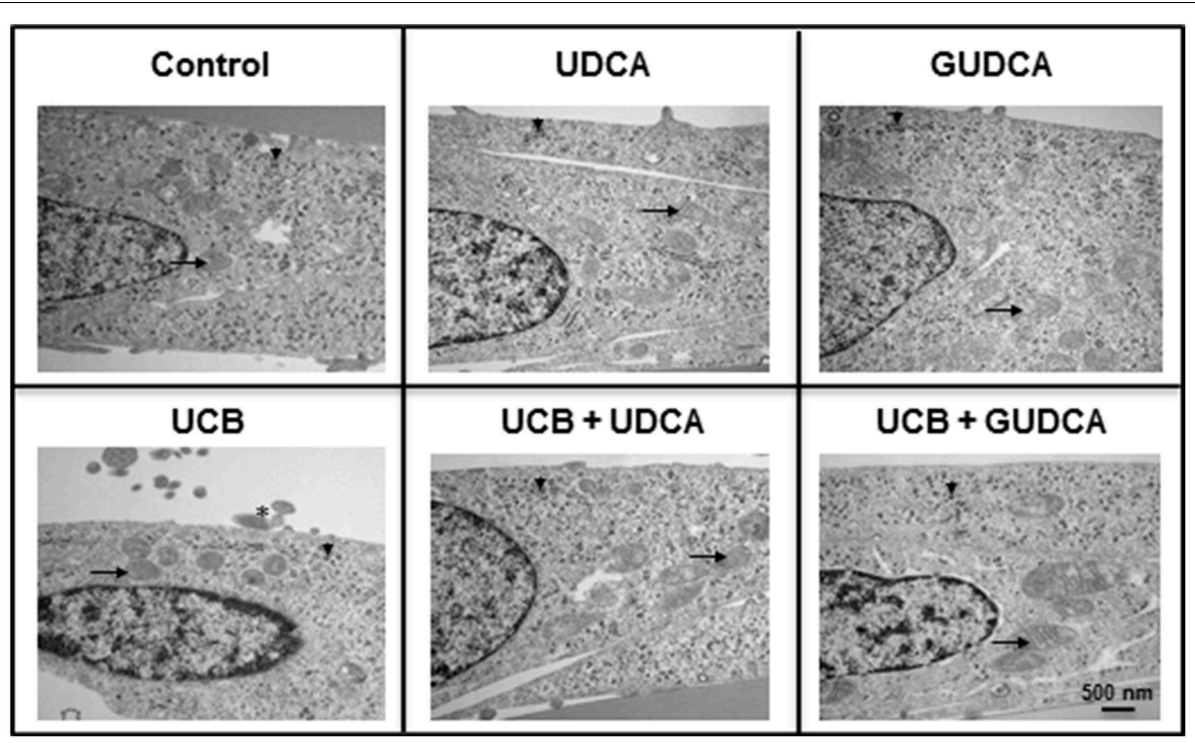

FIGURE 3 | Ursodeoxycholic acid (UDCA) and glycoursodeoxycholic acid (GUDCA) have protective effects on unconjugated bilirubin (UCB)-induced ultrastructural changes in human brain microvascular endothelial cells (HBMEC). A cell line of HBMEC was incubated without (control) or with $100 \mu \mathrm{M}$ UCB, in the presence of $100 \mu \mathrm{M}$ human serum albumin, for $48 \mathrm{~h}$. The bile acids $(50 \mu \mathrm{M})$ were added $1 \mathrm{~h}$ prior to the addition of UCB. Representative ultrastructure observations by transmission electron microscopy are shown. In UCB-treated cells note the decrease in mitochondrial cristae (arrows) and ribosomes (arrowhead) and the appearance of detaching cellular fragments (asterisk), which are abrogated by UDCA and GUDCA.
A

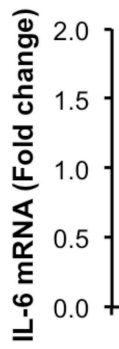

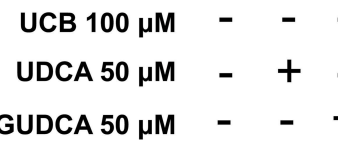

FIGURE 4 | Decrease in unconjugated bilirubin (UCB)-induced interlkeukin (IL)-6 mRNA expression and cytokine release in human brain microvascular endothelila cells (HBMEC) is higher with ursodeoxycholic acid (UDCA) than with

glycoursodeoxycholic acid (GUDCA). A cell line of HBMEC was incubated without (control) or with $100 \mu \mathrm{M} \mathrm{UCB}$, in the presence of $100 \mu \mathrm{M}$ human serum albumin, for 1 or $4 \mathrm{~h}$. The bile acids $(50 \mu \mathrm{M})$

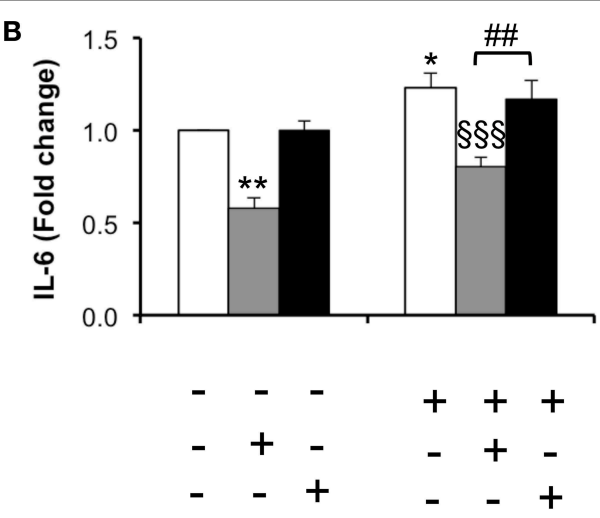

were added $1 \mathrm{~h}$ prior to the addition of UCB. Changes in IL-6 mRNA after $1 \mathrm{~h}$ (A) and protein release after $4 \mathrm{~h}$ of incubation (B) are shown. Quantification is shown as fold change from control values and results are expressed as mean \pm SEM from at least three independent experiments. ${ }^{*} P<0.05,{ }^{* *} P<0.01$, and $* * * P<0.001$ vs. control; $\S P<0.05$ and $\S \S \S P<0.001$ vs. UCB alone; $\# P<0.05$ and $\# \# P<0.01$ UDCA vs. GUDCA. we also observed that UDCA and GUDCA alone do not affect the HBMEC integrity, since we did not observe any changes in permeability values. However, analysis of the bile acids effect on the permeability to sodium fluorescein revealed that only UDCA prevented UCB injury, and if added before (22\% reduction from UCB values, $P<0.01)$ or at $4 \mathrm{~h}(18 \%$ protection from UCB values, $P<0.05)$. In fact, while UCB induced an increased passage of sodium fluorescein molecules from $1.42 \times 10^{-5} \mathrm{~cm} / \mathrm{s}$ in controls to $2.48 \times 10^{-5} \mathrm{~cm} / \mathrm{s}$ in UCB-treated samples, incubation with UDCA reduced such value to $1.95 \times 10^{-5} \mathrm{~cm} / \mathrm{s}$ or to $1.99 \times 10^{-5} \mathrm{~cm} / \mathrm{s}$ in cells pre-treated or treated $4 \mathrm{~h}$ after UCB addition. In contrast, the values obtained for GUDCA were $2.19 \times 10^{-5}$ and $2.24 \times 10^{-5} \mathrm{~cm} / \mathrm{s}$ (pre- and $4 \mathrm{~h}$ after UCB addition treatments, respectively), thus not different from UCB values. 


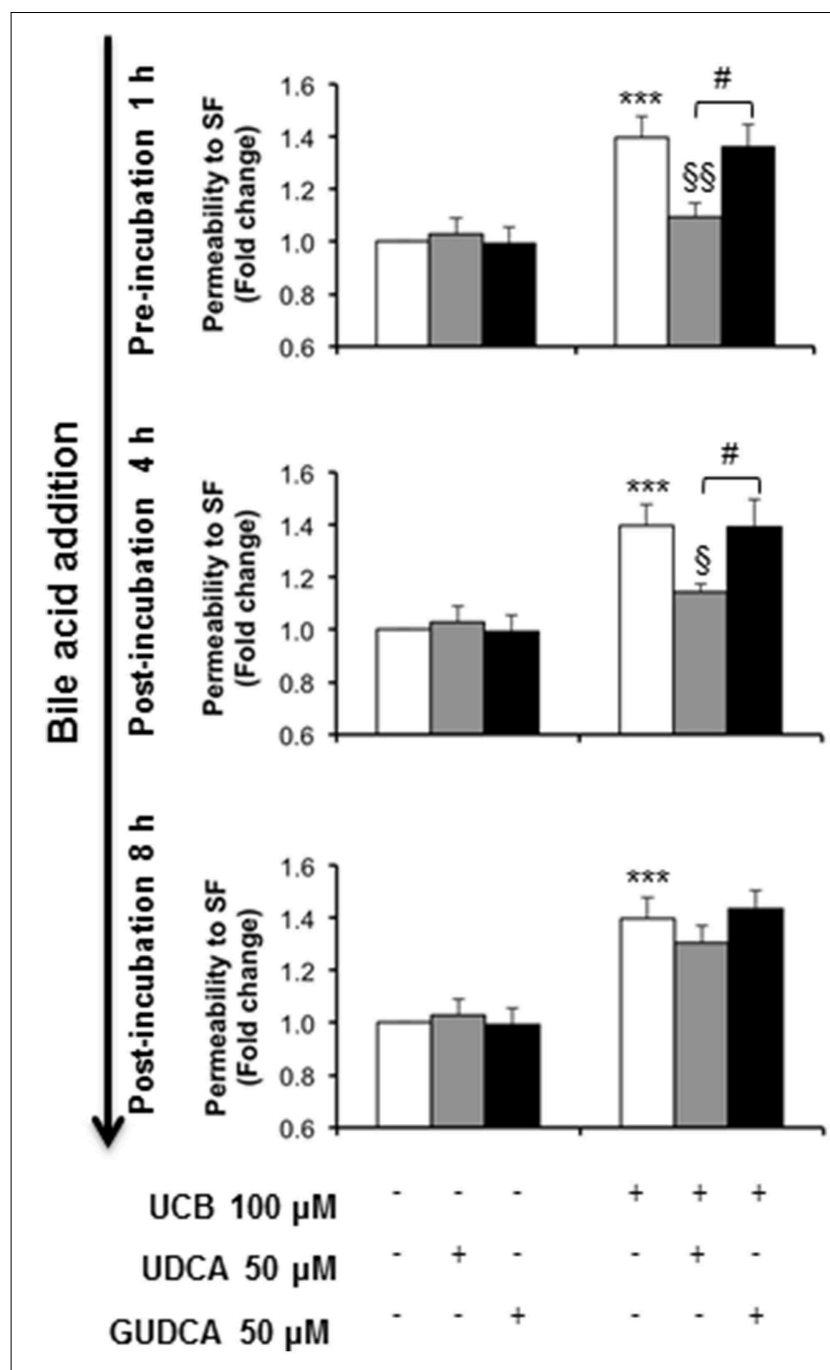

FIGURE 5 | Ursodeoxycholic acid (UDCA), but not glycoursodeoxycholic acid (GUDCA), abrogates paracellular permeability impairment to sodium fluorescein (SF) in human brain microvascular endothelial cells (HBMEC). A cell line of HBMEC was incubated without (control) or with $100 \mu \mathrm{M}$ UCB, in the presence of $100 \mu \mathrm{M}$ human serum albumin, for $48 \mathrm{~h}$. The bile acids $(50 \mu \mathrm{M})$ were added prior to $(1 \mathrm{~h})$ or after ( 4 or $8 \mathrm{~h}$ ) UCB addition. Quantification of permeability to $\mathrm{SF}$ is expressed as fold change from control values and results are shown as mean \pm SEM from at least three independent experiments. ${ }^{* * *} P<0.001$ vs. control; ${ }^{\S} P<0.05$ and $\S \S P<0.01$ vs. UCB alone; $\# P<0.05$ UDCA vs. GUDCA.

\section{UDCA and GUDCA Cross the HBMEC Monolayer in a Time-Dependent Manner}

The addition of $50 \mu \mathrm{M}$ of each of the studied bile acids to the upper ("blood") compartment of an insert culture system was performed to evaluate if they were able to cross the HBMEC monolayer and thus hypothetically achieve the brain parenchyma. After a short period of incubation $(4 \mathrm{~h})$ the bile acids were barely detectable in the lower chamber of the culture plate. However, when longer periods of treatment were applied $(48 \mathrm{~h})$ a significant increase in the bile acid passage through the monolayer was obtained $(18.8 \pm 4.8$ and $16.2 \pm 3.9 \mu \mathrm{M}$, for UDCA and GUDCA, respectively).

\section{Discussion}

In this study we investigated the ability of the bile acid UDCA and its glycine conjugate GUDCA to abrogate the injury caused by UCB in a simplified in vitro model of the human BBB, formed by confluent monolayers of HBMEC. The beneficial role of UDCA and its conjugates on liver-associated pathologies has been extensively addressed in the past (Lazaridis et al., 2001; Paumgartner and Beuers, 2004; Perez and Briz, 2009). Interestingly, it was also demonstrated that these bile acids act as pleiotropic agents and can be used as therapeutic molecules in other non-hepatic pathological conditions, including tumors, hemorrhagic stroke, and neurodegenerative disorders like amyotrophic lateral sclerosis (Min et al., 2012), Huntington's (Keene et al., 2002), Alzheimer's (Solá et al., 2003), and Parkinson's diseases (Duan et al., 2002). We have previously shown that UDCA and/or GUDCA have protective properties in reducing the UCBmediated induction of cell death in both neurons and astrocytes (Silva et al., 2001b; Fernandes et al., 2007b; Vaz et al., 2010). Moreover, we observed the beneficial effects of these bile acids in reducing the increased secretion of pro-inflammatory cytokines by astrocytes and microglia treated with UCB (Fernandes et al., 2007b; Silva et al., 2012) and the oxidative injury in neurons exposed to UCB (Brito et al., 2008), as reviewed by Brites (2012). Importantly, numerous studies have demonstrated that these specific therapeutic properties of UDCA and its conjugates do not apply to the more hydrophobic bile acids. In fact, deoxycholic acid (hydrophobic bile acid) was shown to increase lipid polarity and fluidity, while UDCA and TUDCA (hydrophilic bile acids) are able to reverse such effects (Solá et al., 2002). Additionally, UDCA demonstrated to protect neurons from UCB toxicity, while other hydrophobic bile acids like cholic and chenodeoxycholic acids even aggravated UCB injury (Silva et al., 2001b). The same was observed with endothelial cells where deoxycholic and taurochenodeoxycholic acids caused the cell lysis by acting as detergents (Greenwood et al., 1991) while TUDCA revealed beneficial effects in preventing cell damage by other injurious conditions (Viana et al., 2009; Vladykovskaya et al., 2012). Thus, we aimed to understand if the unconjugated species UDCA and the most predominant conjugate GUDCA derivative, with LogP values of 3.0 and 2.02, respectively (Roda et al., 1990), in humans had protective properties in our simplified in vitro model of the $\mathrm{BBB}$ in conditions mimicking severe hyperbilirubinemia.

Our previous studies have shown that the BMEC response to UCB is extremely elaborate and far more complex than formerly thought. Our in vitro findings include the elevation of endothelial cell death, the upregulation of caveolae and caveolin-1 levels, the increased production of interleukin-6, and the release of matrix metalloproteinases (Palmela et al., 2011, 2012; Cardoso et al., 2012). Consequently, these events led to junction weakness, as well as disruption of endothelial barrier integrity. To such disruption may also contribute the impairment of the cytoskeleton organization induced by UCB (Silva et al., 2001a, 2006), which is known to compromise the intercellular junctions assembly and 
lead to an increased paracellular permeability (Cardoso et al., 2010). Thus, in addition to diffusion of free bilirubin across the brain microvascular endothelium, the paracellular hyperpermeability of the microvasculature may further favor the freely movement of free bilirubin, as well as of UCB-bound to albumin, via the paracellular space. Also interesting is the increased caveolin-1 expression and the enhanced number of caveolae (Palmela et al., 2012) since caveolae are known to transport albumin, which raises the possibility of augmented entrance of albumin-bound UCB by the transcellular pathway. Validating these in vitro findings, signs of $\mathrm{BBB}$ compromise were also observed in some brain regions of human cases of neonatal kernicterus, including albumin presence in the brain parenchyma, increased vascularization and microvascular hyperpermeability (Brito et al., 2012, 2013), reduced pericyte vascular coverage and loss of basement membrane components (Palmela et al., submitted). These findings suggest that the $\mathrm{BBB}$ plays an important role in the progression of brain damage by severe hyperbilirubinemia and, thus, that this interface should be considered when studying this pathology.

Here, we intended to evaluate the effects of UDCA and GUDCA at the time-point corresponding to the most significant UCB-induced injury previously observed. Furthermore, as UCB effects on HBMEC were also concentration-dependent, we focused on the concentration with the most disruptive potential regarding the integrity of HBMEC $(100 \mu \mathrm{M}$ UCB in the presence of $100 \mu \mathrm{M}$ human serum albumin), which corresponds to the bilirubin:albumin ratio that induces acute bilirubin encephalopathy and kernicterus (Brito et al., 2012; Iskander et al., 2014) and to free bilirubin values found in jaundiced neonates (Brito, 2001; Ahlfors et al., 2009). To assess the therapeutic window of opportunity of GUDCA and UDCA we tested bile acid efficacy when used before (prevention), or at 4 and $8 \mathrm{~h}$ after UCB addition (recovery). To further understand if such bile acids can be promising candidates to rescue neural function in brain diseases we assessed their capacity to cross the HBMEC monolayer, here used as an in vitro model of BBB.

Bile acids revealed a high capacity in protecting HBMEC from UCB-induced apoptosis. Interestingly, GUDCA was the most effective against apoptotic features and caspase- 3 activation, and was able to restore basal levels, even when the injury was already initiated. Although the anti-apoptotic role of UDCA has been documented in hepatic and non-hepatic cells (Amaral et al., 2009a), the findings here reported are the first in a simplified in vitro model of the human BBB. Interestingly, apoptotic cell death results in increased permeability (Erdbruegger et al., 2006), rendering conceivable that the mechanisms underlying HBMEC protection may involve the anti-apoptotic properties of the bile acids. Regardless of the mechanism(s) involved in the protection, the present study opens new avenues for treatment of neurodegenerative diseases that have increasingly been associated with endothelial demise and BBB disruption (Zlokovic, 2008).

When analysing the possible ultrastructural changes produced by UCB and their recovery by the bile acids, we noticed that the loss of ribosomes in UCB-treated samples was reverted by both UDCA and GUDCA. Alterations in ribosomes were associated with apoptosis (Nishida et al., 2002) and autophagy (Cebollero et al., 2012), phenomena already observed in HBMEC treated with UCB (Palmela et al., 2011, 2012). Indeed, Hansen et al. (2001) found elevated levels of bilirubin in ribosomes following exposure of rats to hyperbilirubinemia and hyperosmolality, recognized as a risk factor of kernicterus by increasing BBB permeability (Wennberg, 2000). Therefore, it is tentative to speculate that UCB may induce HBMEC ribophagy, a recent term do designate autophagic turnover of ribosomes (Cebollero et al., 2012), and that both bile acids are able to prevent and recover such event from occurring.

The transmission electron microscopy analysis provided further information about the toxicity of UCB to other cell organelles, particularly the mitochondria. Our observations highlighted a loss of mitochondrial cristae after UCB exposure, which appeared to be restored in HBMEC pre-incubated with each of the bile acids. In a recent study, damaged mitochondria in the presence of UCB were identified in rat BMEC (Cardoso et al., 2012). Mitochondria has been considered one of the first targets of UCB injury to the cells (Mustafa and King, 1970), showing accumulation of glycogen, a sign of impaired energetic function (Batty and Millhouse, 1976). Other studies, including several from our own group, have shown loss of mitochondrial membrane potential, release of cytochrome $c$, and impaired cytochrome $c$ oxidase activity (Rodrigues et al., 2000, 2002a; Malik et al., 2010; Barateiro et al., 2012). To note that the protective ability of the bile acids, especially UDCA, in preventing mitochondria dysfunction by UCB was shown in some of those studies (Rodrigues et al., 2000, 2002a). Moreover, the mitochondria enlargement that seems to occur in cells treated with GUDCA and UCB may represent a mechanism to protect cells from apoptotic stimuli (Chiche et al., 2010). Detachment of cellular fragments in UCB-treated samples is in line with the release of small vesicles from HBMEC already noticed by scanning electron microscopy (Palmela et al., 2012). All these features corroborate the previously demonstrated interaction of UCB with membranes (Brites and Brito, 2012) and the stabilizing effect of the bile acids at this level (Rodrigues et al., 2002b; Solá et al., 2002).

Amongst the cytokines produced by HBMEC upon UCB interaction is interleukin-6 (Palmela et al., 2011), a cytokine that has been reported to induce the disruption of the BBB (Maruo et al., 1992; De Vries et al., 1996). Only UDCA was able to reduce both interleukin- 6 mRNA expression and protein release. Compromised $\mathrm{BBB}$ by vascular leak and tight junction disassembly may lead to deregulated flux of molecules and loss of brain homeostasis. Thus, the restorative effects of the bile acids in interleukin-6 levels may contribute to sustain HBMEC integrity in the presence of UCB. While GUDCA revealed strong antiapoptotic effects, UDCA was more effective in preventing the increased interleukin- 6 secretion by HBMEC treated with UCB. Interestingly, UDCA was also more able than GUDCA in rescuing HBMEC from the increased permeability induced by UCB, an effect that was observed even if the bile acid was added $4 \mathrm{~h}$ after UCB-addition. Such dissimilarities among the bile acids species may derive from the different changes that UDCA and the conjugated species were shown to produce in the composition of membrane lipid content (Bellentani et al., 1996). 
Crossing the $\mathrm{BBB}$ is one of the main milestones for therapeutic molecules that are meant to act in the brain. Although detection of UDCA and its taurine conjugate was found in the brain parenchyma after injection in rodents (Kaemmerer et al., 2001; Rodrigues et al., 2003; Parry et al., 2010) and in the cerebrospinal fluid after oral administration in patients with amyotrophic lateral sclerosis (Parry et al., 2010), no studies were till now performed using HBMEC. Here, we show that both UDCA and GUDCA cross the HBMEC monolayer, in vitro. However, the mechanism underlying the passage of the bile acids across the $\mathrm{BBB}$ has never been reported. Among the factors that may influence $\mathrm{BBB}$ permeation are the bile acids' physico-chemical characteristics, namely their octanol/water partition coefficient (Roda et al., 1990), and the presence of several transporters at the BBB (Abbott et al., 2010) that may modulate their passage across the endothelium. Therefore, additional studies are necessary to establish the mechanism involved in these bile acids passage across the BBB. The suggested potential therapeutic role for UDCA and GUDCA also needs further evaluation in animal models of severe jaundice, such as the Gunn rat (Gunn, 1938) or the glucuronosyl-transferase knock-out mice (Nguyen et al., 2008).

Collectively, our in vitro data show that the disruption of endothelial cell function and BBB dynamic properties by exposure to UCB in conditions mimicking a severe neonatal jaundice can be prevented and partially restored by UDCA and GUDCA.

\section{References}

Abbott, N. J., Patabendige, A. A., Dolman, D. E., Yusof, S. R., and Begley, D. J. (2010). Structure and function of the blood-brain barrier. Neurobiol. Dis. 37, 13-25. doi: 10.1016/j.nbd.2009.07.030

Ahlfors, C. E., Wennberg, R. P., Ostrow, J. D., and Tiribelli, C. (2009). Unbound (free) bilirubin: improving the paradigm for evaluating neonatal jaundice. Clin. Chem. 55, 1288-1299. doi: 10.1373/clinchem.2008.121269

Akin, E., Clower, B., Tibbs, R., Tang, J., and Zhang, J. (2002). Bilirubin produces apoptosis in cultured bovine brain endothelial cells. Brain Res. 931, 168-175. doi: 10.1016/S0006-8993(02)02276-X

Amaral, J. D., Viana, R. J., Ramalho, R. M., Steer, C. J., and Rodrigues, C. M. P. (2009a). Bile acids: regulation of apoptosis by ursodeoxycholic acid. J. Lipid Res. 50, 1721-1734. doi: 10.1194/jlr.R900011-JLR200

Amaral, J. D., Viana, R. J., Ramalho, R. M., Steer, C. J., and Rodrigues, C. M. P. (2009b). Bile acids: regulation of apoptosis by ursodeoxycholic acid. J. Lipid Res. 50, 1721-1734. doi: 10.1194/jlr.R900011-JLR200

Barateiro, A., Domingues, H. S., Fernandes, A., Relvas, J. B., and Brites, D. (2014). Rat cerebellar slice cultures exposed to bilirubin evidence reactive gliosis, excitotoxicity and impaired myelinogenesis that is prevented by AMPA and TNFalpha inhibitors. Mol. Neurobiol. 49, 424-439. doi: 10.1007/s12035-013-8530-7

Barateiro, A., Vaz, A. R., Silva, S. L., Fernandes, A., and Brites, D. (2012). ER stress, mitochondrial dysfunction and calpain/JNK activation are involved in oligodendrocyte precursor cell death by unconjugated bilirubin. Neuromol. Med. 14, 285-302. doi: 10.1007/s12017-012-8187-9

Batty, H. K., and Millhouse, O. E. (1976). Ultrastructure of the Gunn rat substantia nigra I. Cytoplasmic changes. Acta Neuropathol. 35, 93-107. doi: 10.1007/BF00690556

Bellentani, S., Chao, Y. C., Ferretti, I., Panini, R., and Tiribelli, C. (1996). Chronic administration of ursodeoxycholic and tauroursodeoxycholic acid changes microsomal membrane lipid content and fatty acid compositions in rats. Biochem. Biophys. Res. Commun. 220, 479-483. doi: 10.1006/bbrc. 1996.0430
The results also show a higher efficacy when the bile acids are administered before injury, reinforcing their preventive effects. They further show that both molecules slowly permeate across the $\mathrm{BBB}$ endothelium, which points to their potential to reach the brain and elicit therapeutic properties in target cells.

\section{Author Contributions}

IP, performed most of the experimental work, analyzed data and drafted the manuscript; LC, RFMS, HS, and KSK contributed to the acquisition, analysis and interpretation of the data, as well as to the review of the manuscript. DB contributed to the analysis and interpretation of data, and critically revised the manuscript. MAB designed the work, contributed to the acquisition, analysis and interpretation of data, and critically revised the manuscript. All the authors approved the version to be published and provided agreement to be accountable for all aspects of the work.

\section{Acknowledgments}

This work was supported by FEDER (COMPETE Programme) and by National funds (FCT - Fundação para a Ciência e a Tecnologia): project PEst-OE/SAU/UI4013/2011-2013 to iMed.ULisboa, PTDC/SAU-FCF/68819/2006 (to MAB), and a PhD fellowship (SFRH/BD/61646/2009) to IP.

Brites, D. (2012). The evolving landscape of neurotoxicity by unconjugated bilirubin: role of glial cells and inflammation. Front. Pharmacol. 3:88. doi: 10.3389/fphar.2012.00088

Brites, D., and Brito, M. A. (2012). "Bilirubin toxicity," in Care of The Jaundiced Neonate, eds D. K. Stevenson, M. J. Maisels and J. F. Watchko (New York, NY: Mc-Graw-Hill Companies, Inc.), 115-143.

Brites, D., Rodrigues, C. M. P., Van-Zeller, H., Brito, A., and Silva, R. (1998). Relevance of serum bile acid profile in the diagnosis of intrahepatic cholestasis of pregnancy in an high incidence area: Portugal. Eur. J. Obstet. Gynecol. Reprod. Biol. 80, 31-38. doi: 10.1016/S0301-2115(98)00086-4

Brito, M. A. (2001). Interacção da Bilirrubina Com o Eritrócito. Espécies Moleculares Envolvidas, Estádios de Toxicidade e Comportamento da Célula Fetal. $\mathrm{PhD}$ Thesis, Faculty of Pharmacy, University of Lisbon.

Brito, M. A., Brites, D., and Butterfield, D. A. (2004). A link between hyperbilirubinemia, oxidative stress and injury to neocortical synaptosomes. Brain Res. 1026, 33-43. doi: 10.1016/j.brainres.2004.07.063

Brito, M. A., Lima, S., Fernandes, A., Falcão, A. S., Silva, R. F. M., Butterfield, D. A., et al. (2008). Bilirubin injury to neurons: contribution of oxidative stress and rescue by glycoursodeoxycholic acid. Neurotoxicology 29, 259-269. doi: 10.1016/j.neuro.2007.11.002

Brito, M. A., Pereira, P., Barroso, C., Aronica, E., and Brites, D. (2013). New autopsy findings in different brain regions of a preterm neonate with kernicterus: neurovascular alterations and up-regulation of efflux transporters. Pediatr. Neurol. 49, 431-438. doi: 10.1016/j.pediatrneurol.2013. 08.020

Brito, M. A., Silva, R., Tiribelli, C., and Brites, D. (2000). Assessment of bilirubin toxicity to erythrocytes. Implication in neonatal jaundice management. Eur. J. Clin. Invest. 30, 239-247. doi: 10.1046/j.1365-2362.2000. 00612.x

Brito, M. A., Zurolo, E., Pereira, P., Barroso, C., Aronica, E., and Brites, D. (2012) Cerebellar axon/myelin loss, angiogenic sprouting, and neuronal increase of vascular endothelial growth factor in a preterm infant with kernicterus. J. Child Neurol. 27, 615-624. doi: 10.1177/0883073811423975 
Cardoso, F. L., Brites, D., and Brito, M. A. (2010). Looking at the blood-brain barrier: molecular anatomy and possible investigation approaches. Brain Res. Rev. 64, 328-363. doi: 10.1016/j.brainresrev.2010.05.003

Cardoso, F. L., Kittel, A., Veszelka, S., Palmela, I., Toth, A., Brites, D., et al. (2012). Exposure to lipopolysaccharide and/or unconjugated bilirubin impair the integrity and function of brain microvascular endothelial cells. PLOS ONE 7:e35919. doi: 10.1371/journal.pone.0035919

Carvey, P. M., Hendey, B., and Monahan, A. J. (2009). The blood-brain barrier in neurodegenerative disease: a rhetorical perspective. J. Neurochem. 111, 291-314. doi: 10.1111/j.1471-4159.2009.06319.x

Cebollero, E., Reggiori, F., and Kraft, C. (2012). Reticulophagy and ribophagy: regulated degradation of protein production factories. Int. J. Cell Biol. 2012:182834. doi: 10.1155/2012/182834

Chiche, J., Rouleau, M., Gounon, P., Brahimi-Horn, M. C., Pouyssegur, J., and Mazure, N. M. (2010). Hypoxic enlarged mitochondria protect cancer cells from apoptotic stimuli. J. Cell. Physiol. 222, 648-657. doi: 10.1002/jcp.21984

Cho, J. G., Lee, J. H., Hong, S. H., Lee, H. N., Kim, C. M., Kim, S. Y., et al. (2015). Tauroursodeoxycholic acid, a bile acid, promotes blood vessel repair by recruiting vasculogenic progenitor cells. Stem Cells. 33, 792-805. doi: 10.1002/stem.1901

Cohen, R. S., Wong, R. J., and Stevenson, D. K. (2010). Understanding neonatal jaundice: a perspective on causation. Pediatr. Neonatol. 51, 143-148. doi: 10.1016/S1875-9572(10)60027-7

Deli, M. A., Abraham, C. S., Kataoka, Y., and Niwa, M. (2005). Permeability studies on in vitro blood-brain barrier models: physiology, pathology, and pharmacology. Cell. Mol. Neurobiol. 25, 59-127. doi: 10.1007/s10571-004-1377-8

De Vries, H. E., Blom-Roosemalen, M. C., Van Oosten, M., De Boer, A. G., Van Berkel, T. J., Breimer, D. D., et al. (1996). The influence of cytokines on the integrity of the blood-brain barrier in vitro. J. Neuroimmunol. 64, 37-43. doi: 10.1016/0165-5728(95)00148-4

Duan, W. M., Rodrigues, C. M. P., Zhao, L. R., Steer, C. J., and Low, W. C. (2002). Tauroursodeoxycholic acid improves the survival and function of nigral transplants in a rat model of Parkinson's disease. Cell Transplant. 11, 195-205. doi: 10.0000/096020198389960

Eigenmann, D. E., Xue, G., Kim, K. S., Moses, A. V., Hamburger, M., and Oufir, M. (2013). Comparative study of four immortalized human brain capillary endothelial cell lines, hCMEC/D3, hBMEC, TY10, and BB19, and optimization of culture conditions, for an in vitro blood-brain barrier model for drug permeability studies. Fluids Barriers CNS 10:33. doi: 10.1186/2045-81 18-10-33

Erdbruegger, U., Haubitz, M., and Woywodt, A. (2006). Circulating endothelial cells: a novel marker of endothelial damage. Clin. Chim. Acta 373, 17-26. doi: 10.1016/j.cca.2006.05.016

Falcão, A. S., Fernandes, A., Brito, M. A., Silva, R. F. M., and Brites, D. (2006). Bilirubin-induced immunostimulant effects and toxicity vary with neural cell type and maturation state. Acta Neuropathol. 112, 95-105. doi: 10.1007/s00401006-0078-4

Fernandes, A., Falcão, A. S., Silva, R. F. M., Brito, M. A., and Brites, D. (2007a). MAPKs are key players in mediating cytokine release and cell death induced by unconjugated bilirubin in cultured rat cortical astrocytes. Eur. J. Neurosci. 25, 1058-1068. doi: 10.1111/j.1460-9568.2007.05340.x

Fernandes, A., Falcão, A. S., Silva, R. F. M., Gordo, A. C., Gama, M. J., Brito, M. A., et al. (2006). Inflammatory signalling pathways involved in astroglial activation by unconjugated bilirubin. J. Neurochem. 96, 1667-1679. doi: 10.1111/j.14714159.2006.03680.x

Fernandes, A., Vaz, A. R., Falcão, A. S., Silva, R. F. M., Brito, M. A., and Brites, D. (2007b). Glycoursodeoxycholic acid and interleukin-10 modulate the reactivity of rat cortical astrocytes to unconjugated bilirubin. J. Neuropathol. Exp. Neurol. 66, 789-798. doi: 10.1097/nen.0b013e3181461c74

Greenwood, J., Adu, J., Davey, A. J., Abbott, N. J., and Bradbury, M. W. (1991). The effect of bile salts on the permeability and ultrastructure of the perfused, energydepleted, rat blood-brain barrier. J. Cereb. Blood Flow Metab. 11, 644-654. doi: 10.1038/jcbfm.1991.116

Gunn, C. H. (1938). Hereditary acholuric jaundice in a new mutant strain of rats. $J$ Hereditary 29, 137-139.

Hansen, T. W. R., Tommarello, S., and Allen, J. (2001). Subcellular localization of bilirubin in rat brain after in vivo i.v. administration of $[3 \mathrm{H}]$ bilirubin. Pediatr. Res. 49, 203-207. doi: 10.1203/00006450-200102000-00012
Hülper, P., Veszelka, S., Walter, F. R., Wolburg, H., Fallier-Becker, P., Piontek, J., et al. (2013). Acute effects of short-chain alkylglycerols on blood-brain barrier properties of cultured brain endothelial cells. Br. J. Pharmacol. 169, 1561-1573. doi: $10.1111 /$ bph. 12218

Iskander, I., Gamaleldin, R., El Houchi, S., El Shenawy, A., Seoud, I., El Gharbawi, N., et al. (2014). Serum bilirubin and bilirubin/albumin ratio as predictors of bilirubin encephalopathy. Pediatrics 134, e1330-e1339. doi: 10.1542/peds.20131764

Kaemmerer, W. F., Rodrigues, C. M., Steer, C. J., and Low, W. C. (2001). Creatinesupplemented diet extends purkinje cell survival in spinocerebellar ataxia type 1 transgenic mice but does not prevent the ataxic phenotype. Neuroscience 103, 713-724. doi: 10.1016/S0306-4522(01)00017-3

Kapitulnik, J., Benaim, C., and Sasson, S. (2012). Endothelial cells derived from the blood-brain barrier and islets of langerhans differ in their response to the effects of bilirubin on oxidative stress under hyperglycemic conditions. Front. Pharmacol. 3:131. doi: 10.3389/fphar.2012.00131

Kaur, C., and Ling, E. A. (2008). Blood brain barrier in hypoxic-ischemic conditions. Curr. Neurovasc. Res. 5, 71-81. doi: 10.2174/156720208783565645

Keene, C. D., Rodrigues, C. M. P., Eich, T., Chhabra, M. S., Steer, C. J., and Low, W. C. (2002). Tauroursodeoxycholic acid, a bile acid, is neuroprotective in a transgenic animal model of Huntington's disease. Proc. Natl. Acad. Sci. U.S.A. 99, 10671-10676. doi: 10.1073/pnas.162362299

Labus, J., Hackel, S., Lucka, L., and Danker, K. (2014). Interleukin-1beta induces an inflammatory response and the breakdown of the endothelial cell layer in an improved human THBMEC-based in vitro blood-brain barrier model. J. Neurosci. Methods 228, 35-45. doi: 10.1016/j.jneumeth.2014.03.002

Lazaridis, K. N., Gores, G. J., and Lindor, K. D. (2001). Ursodeoxycholic acid 'mechanisms of action and clinical use in hepatobiliary disorders'. J. Hepatol. 35, 134-146. doi: 10.1016/S0168-8278(01)00092-7

Ma, J., Iida, H., Jo, T., Takano, H., Oonuma, H., Morita, T., et al. (2004). Ursodeoxycholic acid inhibits endothelin-1 production in human vascular endothelial cells. Eur. J. Pharmacol. 505, 67-74. doi: 10.1016/j.ejphar.2004.10.042

Malik, S. G., Irwanto, K. A., Ostrow, J. D., and Tiribelli, C. (2010). Effect of bilirubin on cytochrome $c$ oxidase activity of mitochondria from mouse brain and liver. BMC Res. Notes 3:162. doi: 10.1186/1756-0500-3-162

Maruo, N., Morita, I., Shirao, M., and Murota, S. (1992). IL-6 increases endothelial permeability in vitro. Endocrinology 131, 710-714.

Mcdonagh, A. F., and Assisi, F. (1972). The ready isomerization of bilirubin IX- $\alpha$ in aqueous solution. Biochem. J. 129, 797-800.

Min, J. H., Hong, Y. H., Sung, J. J., Kim, S. M., Lee, J. B., and Lee, K. W. (2012). Oral solubilized ursodeoxycholic acid therapy in amyotrophic lateral sclerosis: a randomized cross-over trial. J. Korean Med. Sci. 27, 200-206. doi: 10.3346/jkms.2012.27.2.200

Mustafa, M. G., and King, T. E. (1970). Binding of bilirubin with lipid. A possible mechanism of its toxic reactions in mitochondria. J. Biol. Chem. 245, 1084-1089.

Nguyen, N., Bonzo, J. A., Chen, S., Chouinard, S., Kelner, M. J., Hardiman, G., et al. (2008). Disruption of the ugt1 locus in mice resembles human CriglerNajjar type I disease. J. Biol. Chem. 283, 7901-7911. doi: 10.1074/jbc.M709 244200

Nishida, J., Shiratsuchi, A., Nadano, D., Sato, T. A., and Nakanishi, Y. (2002). Structural change of ribosomes during apoptosis: degradation and externalization of ribosomal proteins in doxorubicin-treated Jurkat cells. J. Biochem. 131, 485-493. doi: 10.1093/oxfordjournals.jbchem.a003125

Palmela, I., Cardoso, F. L., Bernas, M., Correia, L., Vaz, A. R., Silva, R. F. M., et al. (2011). Elevated levels of bilirubin and long-term exposure impair human brain microvascular integrity Curr. Neurovasc. Res. 8, 153-169. doi: $10.2174 / 156720211795495358$

Palmela, I., Sasaki, H., Cardoso, F. L., Moutinho, M., Kim, K. S., Brites, D., et al. (2012). Time-dependent dual effects of high levels of unconjugated bilirubin on the human blood-brain barrier lining. Front. Cell. Neurosci. 6:22. doi: $10.3389 /$ fncel.2012.00022

Parry, G. J., Rodrigues, C. M. P., Aranha, M. M., Hilbert, S. J., Davey, C., Kelkar, P., et al. (2010). Safety, tolerability, and cerebrospinal fluid penetration of ursodeoxycholic acid in patients with amyotrophic lateral sclerosis. Clin. Neuropharmacol. 33, 17-21. doi: 10.1097/WNF.0b013e318 $1 c 47569$ 
Paumgartner, G., and Beuers, U. (2004). Mechanisms of action and therapeutic efficacy of ursodeoxycholic acid in cholestatic liver disease. Clin. Liver. Dis. 8, 67-81, vi. doi: 10.1016/S1089-3261(03)00135-1

Perez, M. J., and Briz, O. (2009). Bile-acid-induced cell injury and protection. World J. Gastroenterol. 15, 1677-1689. doi: 10.3748/wjg.15.1677

Podda, M., Ghezzi, C., Battezzati, P. M., Crosignani, A., Zuin, M., and Roda, A. (1990). Effects of ursodeoxycholic acid and taurine on serum liver enzymes and bile acids in chronic hepatitis. Gastroenterology 98, 1044-1050. doi: 10.1016/0016-5085(90)90032-V

Poupon, R. E., Poupon, R., and Balkau, B. (1994). Ursodiol for the long-term treatment of primary biliary cirrhosis. The UDCA-PBC study group. N. Engl. J. Med. 330, 1342-1347. doi: 10.1056/NEJM199405123301903

Roca, L., Calligaris, S., Wennberg, R. P., Ahlfors, C. E., Malik, S. G., Ostrow, J. D., et al. (2006). Factors affecting the binding of bilirubin to serum albumins: validation and application of the peroxidase method. Pediatr. Res. 60, 724-728. doi: 10.1203/01.pdr.0000245992.89965.94

Roda, A., Minutello, A., Angellotti, M. A., and Fini, A. (1990). Bile acid structureactivity relationship: evaluation of bile acid lipophilicity using 1-octanol/water partition coefficient and reverse phase HPLC. J. Lipid Res. 31, 1433-1443.

Rodrigues, C. M. P., Solá, S., and Brites, D. (2002a). Bilirubin induces apoptosis via the mitochondrial pathway in developing rat brain neurons. Hepatology 35 , 1186-1195. doi: 10.1053/jhep.2002.32967

Rodrigues, C. M. P., Solá, S., Brito, M. A., Brites, D., and Moura, J. J. G. (2002b). Bilirubin directly disrupts membrane lipid polarity and fluidity, protein order, and redox status in rat mitochondria. J. Hepatol. 36, 335-341. doi: 10.1016/S0168-8278(01)00279-3

Rodrigues, C. M. P., Solá, S., Brito, M. A., Brondino, C. D., Brites, D., and Moura, J. J. G. (2001). Amyloid beta-peptide disrupts mitochondrial membrane lipid and protein structure: protective role of tauroursodeoxycholate. Biochem. Biophys. Res. Commun. 281, 468-474. doi: 10.1006/bbrc.2001.4370

Rodrigues, C. M. P., Solá, S., Nan, Z., Castro, R. E., Ribeiro, P. S., Low, W. C., et al. (2003). Tauroursodeoxycholic acid reduces apoptosis and protects against neurological injury after acute hemorrhagic stroke in rats. Proc. Natl. Acad. Sci. U.S.A. 100, 6087-6092. doi: 10.1073/pnas.1031632100

Rodrigues, C. M. P., Solá, S., Silva, R., and Brites, D. (2000). Bilirubin and amyloidbeta peptide induce cytochrome $\mathrm{c}$ release through mitochondrial membrane permeabilization. Mol. Med. 6, 936-946.

Rudolph, G., Kloeters-Plachky, P., Sauer, P., and Stiehl, A. (2002). Intestinal absorption and biliary secretion of ursodeoxycholic acid and its taurine conjugate. Eur. J. Clin. Invest. 32, 575-580. doi: 10.1046/j.1365-2362.2002.01030.x

Ruiz-Gaspa, S., Dubreuil, M., Guanabens, N., Combalia, A., Peris, P., Monegal, A., et al. (2014). Ursodeoxycholic acid decreases bilirubin-induced osteoblast apoptosis. Eur. J. Clin. Invest. 44, 1206-1214. doi: 10.1111/eci.12355

Silva, R. F. M., Falcão, A. S., Fernandes, A., Gordo, A. C., Brito, M. A., and Brites, D. (2006). Dissociated primary nerve cell cultures as models for assessment of neurotoxicity. Toxicol. Lett. 163, 1-9. doi: 10.1016/j.toxlet.2005.09.033

Silva, R. F. M., Mata, L. M., Gulbenkian, S., and Brites, D. (2001a). Endocytosis in rat cultured astrocytes is inhibited by unconjugated bilirubin. Neurochem. Res. 26, 793-800. doi: 10.1023/A:1011608017870

Silva, R. F. M., Rodrigues, C. M. P., and Brites, D. (2001b). Bilirubin-induced apoptosis in cultured rat neural cells is aggravated by chenodeoxycholic acid but prevented by ursodeoxycholic acid. J. Hepatol. 34, 402-408. doi: 10.1016/S01688278(01)00015-0

Silva, R. F. M., Rodrigues, C. M. P., and Brites, D. (2002). Rat cultured neuronal and glial cells respond differently to toxicity of unconjugated bilirubin. Pediatr. Res. 51, 535-541. doi: 10.1203/00006450-200204000-00022

Silva, S. L., Vaz, A. R., Barateiro, A., Falcão, A. S., Fernandes, A., Brito, M. A., et al. (2010). Features of bilirubin-induced reactive microglia: from phagocytosis to inflammation. Neurobiol. Dis. 40, 663-675. doi: 10.1016/j.nbd.2010.08.010
Silva, S. L., Vaz, A. R., Diógenes, M. J., Van Rooijen, N., Sebastião, A. M., Fernandes, A., et al. (2012). Neuritic growth impairment and cell death by unconjugated bilirubin is mediated by NO and glutamate, modulated by microglia, and prevented by glycoursodeoxycholic acid and interleukin-10. Neuropharmacology 62, 2398-2408. doi: 10.1016/j.neuropharm.2012.02.002

Solá, S., Brito, M. A., Brites, D., Moura, J. J. G., and Rodrigues, C. M. P. (2002). Membrane structural changes support the involvement of mitochondria in the bile salt-induced apoptosis of rat hepatocytes. Clin. Sci. (Lond) 103, 475-485. doi: $10.1042 / \mathrm{CS} 20020196$

Solá, S., Castro, R. E., Laires, P. A., Steer, C. J., and Rodrigues, C. M. P. (2003). Tauroursodeoxycholic acid prevents amyloid-beta peptide-induced neuronal death via a phosphatidylinositol 3-kinase-dependent signaling pathway. Mol. Med. 9, 226-234. doi: 10.2119/2003-00042.Rodrigues

Stins, M. F., Badger, J., and Kim, K. S. (2001). Bacterial invasion and transcytosis in transfected human brain microvascular endothelial cells. Microb. Pathog. 30, 19-28. doi: 10.1006/mpat.2000.0406

Suh, H., Jung, E. J., Kim, T. H., Lee, H. Y., Park, Y. H., and Kim, K. W. (1997). Antiangiogenic activity of ursodeoxycholic acid and its derivatives. Cancer Lett. 113, 117-122. doi: 10.1016/S0304-3835(97)04604-1

Vaz, A. R., Delgado-Esteban, M., Brito, M. A., Bolaños, J. P., Brites, D., and Almeida, A. (2010). Bilirubin selectively inhibits cytochrome $c$ oxidase activity and induces apoptosis in immature cortical neurons: assessment of the protective effects of glycoursodeoxycholic acid. J. Neurochem. 112, 56-65. doi: 10.1111/j.1471-4159.2009.06429.x

Veszelka, S., Pasztoi, M., Farkas, A. E., Krizbai, I., Ngo, T. K., Niwa, M., et al. (2007). Pentosan polysulfate protects brain endothelial cells against bacterial lipopolysaccharide-induced damages. Neurochem. Int. 50, 219-228. doi: 10.1016/j.neuint.2006.08.006

Viana, R. J., Nunes, A. F., Castro, R. E., Ramalho, R. M., Meyerson, J., Fossati, S., et al. (2009). Tauroursodeoxycholic acid prevents E22Q Alzheimer's Abeta toxicity in human cerebral endothelial cells. Cell. Mol. Life Sci. 66, 1094-1104. doi: 10.1007/s00018-009-8746-x

Vladykovskaya, E., Sithu, S. D., Haberzettl, P., Wickramasinghe, N. S., Merchant, M. L., Hill, B. G., et al. (2012). Lipid peroxidation product 4-hydroxy-trans2-nonenal causes endothelial activation by inducing endoplasmic reticulum stress. J. Biol. Chem. 287, 11398-11409. doi: 10.1074/jbc.M111.320416

Wang, C. T., Lin, Y. T., Chiang, B. L., Lin, Y. H., and Hou, S. M. (2006). High molecular weight hyaluronic acid down-regulates the gene expression of osteoarthritis-associated cytokines and enzymes in fibroblast-like synoviocytes from patients with early osteoarthritis. Osteoarthr. Cartil. 14, 1237-1247. doi: 10.1016/j.joca.2006.05.009

Wennberg, R. P. (2000). The blood-brain barrier and bilirubin encephalopathy. Cell. Mol. Neurobiol. 20, 97-109. doi: 10.1023/A:1006900111744

Woo, S. J., Kim, J. H., and Yu, H. G. (2010). Ursodeoxycholic acid and tauroursodeoxycholic acid suppress choroidal neovascularization in a laser-treated rat model. J. Ocul. Pharmacol. Ther. 26, 223-229. doi: 10.1089/jop.2010.0012

Zlokovic, B. V. (2008). The blood-brain barrier in health and chronic neurodegenerative disorders. Neuron 57, 178-201. doi: 10.1016/j.neuron.2008.01.003

Conflict of Interest Statement: The authors declare that the research was conducted in the absence of any commercial or financial relationships that could be construed as a potential conflict of interest.

Copyright (c) 2015 Palmela, Correia, Silva, Sasaki, Kim, Brites and Brito. This is an open-access article distributed under the terms of the Creative Commons Attribution License (CC BY). The use, distribution or reproduction in other forums is permitted, provided the original author(s) or licensor are credited and that the original publication in this journal is cited, in accordance with accepted academic practice. No use, distribution or reproduction is permitted which does not comply with these terms. 